\title{
Uso de clomazone associado ao safener dietholate para o manejo de plantas daninhas na cultura do trigo
}

\author{
Use of clomazone associated with dietholate safener for the management of weeds in wheat crop
Maicon Fernando Schmitz ${ }^{1}$, Leandro Galon ${ }^{1 \star}$, Bruna Piovesan ${ }^{1}$, Matheus Freitas de Souza ${ }^{2}$, Luciane Renata Agazzi ${ }^{1}$, Cesar Tiago Forte ${ }^{1} \&$ Gismael Francisco Perin ${ }^{1}$

${ }^{1}$ Universidade Federal da Fronteira Sul, Erechim, RS, Brasil. *Autor para correspondência: leandro.galone@gmail.com.

${ }^{2}$ Universidade Federal de Viçosa, Viçosa, MG, Brasil.

Submissão: 21/06/2016 / Aceite: 30/10/2017

\begin{abstract}
RESUMO
O uso intensivo e repetido do método químico de controle na cultura do trigo selecionou populações de nabo (Raphanus raphanistrum e $R$. sativus) e azevém (Lolium multiflorum) resistentes a alguns herbicidas, em especial aos inibidores das enzimas ALS, ACCase e EPSPs. Para manejar as populações de plantas daninhas resistentes, é importante rotacionar os mecanismos de ação de herbicidas, tanto na dessecação como nas aplicações realizadas após a implantação da cultura. Assim, objetivou-se com este trabalho avaliar a eficácia do herbicida clomazone no controle de azevém e nabo, associado ou não ao protetor dietholate, na cultura do trigo. Os experimentos foram conduzidos em delineamento inteiramente casualizado (DIC) com quatro repetições. No ensaio 1 foram testadas doses de dietholate $(0,120,240$, 360 e $480 \mathrm{~g}$ para $100 \mathrm{~kg}$ de sementes de trigo cultivar TBIO Itaipu) e de clomazone (0, 198, 396 e 594 $\mathrm{g} \mathrm{ha}^{-1}$ ) aplicado em pré-emergência. No ensaio 2, instalado de modo simultâneo ao ensaio 1 , os tratamentos foram constituídos pela testemunha infestada, testemunha capinada, clomazone + dietholate (396 $\mathrm{g} \mathrm{ha}^{-1}+240 \mathrm{~g}$ para $100 \mathrm{~kg}$ de semente) - aplicado em pré-emergência, iodosulfuron-methyl $\left(5 \mathrm{~g} \mathrm{ha}^{-1}\right)$ e pyroxsulam (18 $\left.\mathrm{g} \mathrm{ha}^{-1}\right)$ - aplicados em pós-emergência. $O$ tratamento das sementes de trigo com dietholate não interferiu no controle de azevém e nabo pelo clomazone aplicado em pré-emergência. $O$ clomazone, mesmo aplicado em baixas doses, apresentou controle de azevém acima de $80 \%$, podendo ser utilizado para o controle de biótipos resistentes aos herbicidas inibidores da EPSPs, ALS e ACCase. $O$ iodosulfuron-methyl e o pyroxsulam apresentaram excelente controle de nabo e satisfatório de azevém.
\end{abstract}

PALAVRAS-CHAVE: Triticum aestivum, Lolium multiflorum, Raphanus sp.

\begin{abstract}
The intensive and repeated use of the chemical control method in the wheat crop selected populations of turnip (Raphanus raphanistrum and R. sativus) and ryegrass (Lolium multiflorum) resistant to herbicides, especially from the groups of ALS-, ACCase- and EPSPS-inhibitors. It is important to rotate the herbicide mechanisms of action to manage populations of resistant weeds, both in burndown and after planting. Thus, this work aimed to assess the effectiveness of the herbicide clomazone in the control of ryegrass and turnip associated or not to dietholate safener protection in wheat crop. The first experiment was conducted in a completely randomized design (CRD), with four replications. Dietholate doses $(0,120,240$, 360 and $480 \mathrm{~g}$ per $100 \mathrm{~kg}$ of seeds of wheat cultivar TBIO Itaipu) were associated to clomazone doses ( 0 , 198,396 and $594 \mathrm{~g} \mathrm{ha}^{-1}$ ) sprayed pre-emergence. The second experiment comprised infested and weeded control treatments, the pre-emergence application of clomazone + dietholate $\left(396 \mathrm{~g} \mathrm{ha}^{-1}+240 \mathrm{~g}\right.$ per 100 $\mathrm{kg}$ seed) and post-emergence application of iodosulfuron-methyl $\left(5 \mathrm{~g} \mathrm{ha}^{-1}\right)$ or pyroxsulam (18 $\left.\mathrm{g} \mathrm{ha}^{-1}\right)$. The treatment of wheat seeds with dietholate did not affect the control of ryegrass and turnip by clomazone when applied pre-emergence. Clomazone, even when sprayed at low doses, presented ryegrass control above $80 \%$ and can be used to control resistant biotypes of this weed to EPSPs-, ALS- and ACCase-inhibitors. lodosulfuron-methyl and pyroxsulam showed excellent control of turnip and satisfactory control of ryegrass.
\end{abstract}

KEYWORDS: Triticum aestivum, Lolium multiflorum, Raphanus sp. 


\section{INTRODUÇÃO}

A produção de trigo (Triticum aestivum L.) no Brasil atende $60 \%$ da demanda interna e se concentra nos Estados do Paraná e do Rio Grande do Sul (CONAB, 2016). A produtividade dessa cultura varia conforme o cultivar e o manejo dos fatores de produção e do nível tecnológico adotado. Entre os fatores que podem interferir e ocasionar prejuízos ao trigo, destaca-se a interferência das plantas daninhas, pois, quando não controladas, estas ocasionam perdas quantitativas e qualitativas dos grãos colhidos (AGOSTINETTO et al. 2008, GALON et al. 2015).

Das plantas daninhas que interferem no crescimento e desenvolvimento da cultura do trigo, destacam-se o nabo (Raphanus raphanistrum e R. sativus), o azevém (Lolium multiflorum) e a aveia-preta (Avena strigosa) como as mais agressivas e problemáticas de se controlar (LAMEGO et al. 2013). Para o controle dessas plantas daninhas, tem-se utilizado a aplicação de herbicidas, devido à praticidade, à eficiência e ao baixo custo (ROMAN et al. 2006). No entanto, o uso contínuo e repetitivo ao longo das safras de uma única molécula aumentou a pressão de seleção sobre biótipos resistentes. No Brasil, já foi constatada a presença de biótipos de azevém resistentes aos herbicidas inibidores da EPSPs, ACCase e ALS (ROMAN et al. 2004, VARGAS et al. 2013, MARIANI et al. 2015). Além destes, também foram identificados biótipos de nabo resistentes aos inibidores da ALS (COSTA \& RIZZARDI 2014).

Nesse sentido, o herbicida clomazone, que é um inibidor da biossíntese de carotenoides, pode ser uma alternativa interessante para o controle dos biótipos de azevém e de nabo resistente (BOND et al. 2014). Contudo, sabe-se que o clomazone pode causar efeitos fitotóxicos em algumas culturas e que o tratamento de sementes com o safener dietholate vem se mostrando uma alternativa para mitigação destes efeitos em outras culturas (KARAM et al. 2003, SANCHOTENE et al. 2010).

O safener dietholate inibe a enzima citocromo P-450 mono-oxigenase, que é responsável pela ativação do clomazone em plantas (FERHATOGLU et al. 2005). O clomazone precisa ser ativado para a forma 5-ceto clomazone, que é o metabólito do clomazone, sendo esse metabólito que apresenta atividade herbicida (TENBROOK \& TJEERDEMA 2006). A enzima citocromo P-450 mono-oxigenase apresenta nas plantas a função de detoxificação, porém, no caso do clomazone, ela é responsável pela sua oxidação, tornando-o tóxico às plantas que possuem maior capacidade de oxidação (FERHATOGLU et al. 2005, YUN et al. 2005). Com a inibição da enzima citocromo P-450 mono-oxigenase, não há transformação do clomazone, não ocorrendo desse modo a formação do herbicida ativo e, consequentemente, dano à planta (SANCHOTENE et al. 2010).

Assim, objetivou-se com este trabalho avaliar a eficácia do herbicida clomazone no controle de azevém e nabo, associado ou não ao tratamento de sementes de trigo com o safener dietholate.

\section{MATERIAL E MÉTODOS}

Os experimentos foram conduzidos em casa de vegetação da Universidade Federal da Fronteira Sul (UFFS), Campus Erechim, município de Erechim, RS. Vasos de polietileno com capacidade para $8 \mathrm{dm}^{3}$ foram preenchidos com Latossolo Vermelho Aluminoférrico típico, pertencente à unidade de mapeamento Erechim (EMBRAPA 2013). A correção da fertilidade e os demais manejos e tratos culturais foram realizados conforme as recomendações técnicas para a cultura do trigo e do triticale (EMBRAPA 2011). As características químicas e físicas do solo foram: $\mathrm{pH}$ em água de 4,8; $\mathrm{MO}=3,5 \% ; \mathrm{P}=4,0 \mathrm{mg} \mathrm{dm}^{-3} ; \mathrm{K}=117,0$ $\mathrm{mg} \mathrm{dm}{ }^{-3} ; \mathrm{Al}^{3+}=0,6 \mathrm{cmolc} \mathrm{dm}^{-3} ; \mathrm{Ca}^{2+}=4,7 \mathrm{cmolc} \mathrm{dm}^{-3} ; \mathrm{Mg}^{2+}=1,8 \mathrm{cmolc} \mathrm{dm}^{-3} ; \mathrm{CTC}(\mathrm{t})=7,4 \mathrm{cmolc} \mathrm{dm}^{-3}$; $\mathrm{CTC}(\mathrm{TpH}=7,0)=16,5 \mathrm{cmolc} \mathrm{dm}^{-3} ; \mathrm{H}+\mathrm{Al}=9,7 \mathrm{cmolc} \mathrm{dm}^{-3} ; \mathrm{SB}=6,8 \mathrm{cmolc} \mathrm{dm}^{-3} ; \mathrm{V}=41 \%$; e argila $=60 \%$.

$O$ delineamento experimental utilizado foi o inteiramente casualizado, arranjado em esquema fatorial (5 $\times 4$ ), com quatro repetições. No fator A alocaram-se as cinco doses de dietholate $(0,120,240,360 \mathrm{e}$ $480 \mathrm{~g}$ de ingrediente ativo por $100 \mathrm{~kg}$ de semente de trigo). Já no fator $\mathrm{B}$, as quatro doses de clomazone $(0$, 198, 396 e $594 \mathrm{~g} \mathrm{ha}^{-1}$ ) foram aplicadas em pré-emergência. Simultaneamente, realizou-se a condução de um experimento com cinco tratamentos, que foram: testemunha infestada, testemunha capinada, clomazone+dietholate $\left(396+240 \mathrm{~g} \mathrm{ha}^{-1}\right.$ - aplicados em pré-emergência), iodosulfuron-methyl $\left(5 \mathrm{~g} \mathrm{ha}^{-1}\right) \mathrm{e}$ pyroxsulam (18 $\left.\mathrm{g} \mathrm{ha}^{-1}\right)$, sendo os dois últimos aplicados em pós-emergência. Foram semeadas em cada unidade experimental 20 sementes de trigo, 20 de nabo e 20 de azevém em um mesmo vaso, exceto para os tratamentos onde havia a testemunha sem planta daninha, em que só foi cultivado o trigo. A emergência do trigo ocorreu no sexto dia após a semeadura; um dia depois, efetuou-se o desbaste, deixando-se cinco plântulas de cada espécie por unidade experimental.

$\mathrm{O}$ tratamento das sementes de trigo com dietholate foi efetuado diluindo-se o produto em $5 \mathrm{~mL}$ de água e aplicando-o em $500 \mathrm{~g}$ de sementes de trigo, cultivar TBIO Itaipu. Posteriormente, efetuou-se a agitação manual constante por quatro minutos, até que as sementes ficassem com cobertura homogênea. $O$ 
clomazone foi aplicado em pré-emergência, utilizando um pulverizador costal de precisão, pressurizado a $\mathrm{CO}_{2}$, equipado com uma ponta de pulverização da série AXI 110.02, aspergindo um volume de calda de $150 \mathrm{~L} \mathrm{ha}^{-1}$. Os herbicidas iodosulfuron-methyl $\left(5 \mathrm{~g} \mathrm{ha}^{-1}\right)$ e pyroxsulam $\left(18 \mathrm{~g} \mathrm{ha}^{-1}\right)$ foram aplicados em pósemergência, aos 14 dias após a emergência da cultura e das plantas daninhas, com o mesmo equipamento e vazão descritos anteriormente. Ao iodosulfuron-methyl adicionou-se o espalhante adesivo à base de lauril éter sulfato de sódio (Hoefix ${ }^{\circledR}-0,3 \% \mathrm{v} / \mathrm{v}$ ) e, ao pyroxsulam, foi adicionado óleo vegetal (Veget $\mathrm{Oil}^{\circledR}$ $\left.0,5 \mathrm{~L} \mathrm{ha}^{-1}\right)$.

O controle das plantas daninhas foi avaliado aos 5, 19 e 33 dias após a emergência do trigo (DAE) ou aos 21, 28, 35 e 42 dias após a emergência (DAE) das plantas o que equivaleu a 7, 14, 21 e 28 dias após a aplicação dos tratamentos, para os herbicidas constituintes do experimento adicional. A avaliação de controle das plantas daninhas nabo e azevém foi determinada de modo visual, atribuindo-se notas de 0 a $100 \%$, em que 0 significa ausência de controle e 100\%, a morte completa das plantas (SBCPD 1995).

Aos $45 \mathrm{DAE}$, foi realizada ainda a determinação da massa seca das plantas daninhas e do trigo de cada unidade experimental, acondicionando-as em sacos de papel, para secagem em estufa de circulação forçada de ar, a $60 \pm 5^{\circ} \mathrm{C}$, até atingir massa constante.

Os resultados foram submetidos à análise de variância pelo teste F. Havendo significância, compararam-se as doses de clomazone associadas ao dietholate por regressões não lineares, ajustando-se os dados a modelos hiperbólicos com dois parâmetros. Para o experimento adicional, em que se avaliaram os herbicidas padrão (iodosulfuron-methyl e pyroxsulam) juntamente com as testemunhas sem produtos e a melhor dose de clomazone + dietholate, aplicou-se o teste de Tukey. Todos os testes foram efetuados a $5 \%$ de significância.

\section{RESULTADOS E DISCUSSÃO}

Ocorreu interação entre os fatores testados, doses de dietholate e doses de clomazone para todas as variáveis avaliadas. Na Figura 1 são apresentados os resultados de controle de nabo em função da aplicação de doses de clomazone associadas ao dietholate. Observou-se, aos 5 dias após a emergência (DAE), que as maiores doses (396 e $594 \mathrm{~g} \mathrm{ha}^{-1}$ ) do herbicida apresentaram os melhores índices de controle, próximo a $70 \%$, independentemente da associação ou não com o dietholate.

Aos 19 DAE, verificou-se aumento da porcentagem de controle; de modo geral, as duas maiores doses de clomazone novamente mostraram os melhores efeitos, associadas a todas as doses do protetor dietholate (Figura 1). Nessa mesma época de avaliação, a dose de $198 \mathrm{~g} \mathrm{ha}^{-1}$ de clomazone associada a 240 e $360 \mathrm{~g}$ de dietholate, utilizadas em tratamento de $100 \mathrm{~kg}$ de sementes de trigo, ocasionou controle de nabo superior a $89 \%$.

$\mathrm{Na}$ última avaliação, realizada aos $33 \mathrm{DAE}$, naqueles tratamentos onde o nabo não foi totalmente controlado, ocorreu rebrote das plantas, com retomada do crescimento da planta daninha e menor efeito do clomazone (Figura 1). O rebrote do nabo e a retomada do crescimento decorrem da capacidade que essa planta daninha apresenta de recuperar-se da fitotoxicidade e não ser eficientemente controlada por herbicidas aplicados em pré-emergência (SILVA et al. 2010).

Os resultados demonstram que o incremento das doses de clomazone ocasionou o aumento da porcentagem de controle de azevém, ficando acima de $85 \%$, independentemente da dose do protetor aplicada em associação com o herbicida aos 5 DAE (Figura 2). Aos 19 DAE, o uso da menor dose de clomazone (198 $\left.\mathrm{g} \mathrm{ha}^{-1}\right)$, na ausência do protetor, proporcionou controle do azevém superior a $98 \%$. Com o aumento das doses do herbicida, chegou-se a $100 \%$ de controle do azevém, associado ou não ao dietholate.

À medida que o tempo foi passando, houve tendência de aumento do controle do azevém, chegandose aos $33 \mathrm{DAE}$, nas doses de 396 e $594 \mathrm{~g} \mathrm{ha}^{-1}$ de clomazone, a um controle maior que 96\%, independentemente do uso ou não do dietholate (Figura 2). Nessa última avaliação foi observado que a aplicação de todas as doses, exceto a de $120 \mathrm{~g}$ de dietholate por $100 \mathrm{~kg}$ de sementes de trigo associadas ao clomazone, independentemente da dose do herbicida, ocasionou bom controle do azevém: acima de $87 \%$. Esses resultados estão de acordo com os de trabalhos anteriores, que já demonstram a boa eficiência de clomazone no controle de azevém (RIZZARDI \& SERAFINI 2001, BOND et al. 2014).

Os resultados demonstram controle eficiente do azevém, acima de $85 \%$, aos 5 DAE na maior dose de clomazone (594 $\left.\mathrm{g} \mathrm{ha}^{-1}\right)$, independentemente se o trigo havia sido tratado ou não com dietholate (Figura 2). Aos 19 DAE, até mesmo a menor dose do herbicida foi capaz de promover índices de controle do azevém acima de $82 \%$. Em arroz, a aplicação em pré-emergência de baixas doses de clomazone também ocasionou elevada eficiência no controle de poáceas como o capim-arroz (Echinochloa crus-galli) (ZHANG 
et al. 2005, ANDRES et al. 2013). Resultado contrário foi observado para o controle do nabo (Figura 1): mesmo ao usar $594 \mathrm{~g} \mathrm{ha}^{-1}$ (maior dose) de clomazone, não foram atingidos, na associação com dietholate aos $33 \mathrm{DAE}$, índices tão elevados de controle quantos os observados nessa mesma dose e época de avaliação para o controle de azevém, independentemente do uso ou não do protetor (Figura 2). Desse modo, fica evidente que o controle dessas duas espécies infestantes da cultura do trigo apresenta diferenciação em relação às doses aplicadas de clomazone e também no tocante à associação desse herbicida com o protetor de sementes, sendo o azevém mais sensível ao herbicida, com controle médio de $99,3 \%$, e o nabo mais tolerante, com controle médio de $65,85 \%$, levando-se em conta a maior dose aplicada de clomazone (594 $\left.\mathrm{g} \mathrm{ha}^{-1}\right)$, na média de todas as doses de dietholate.
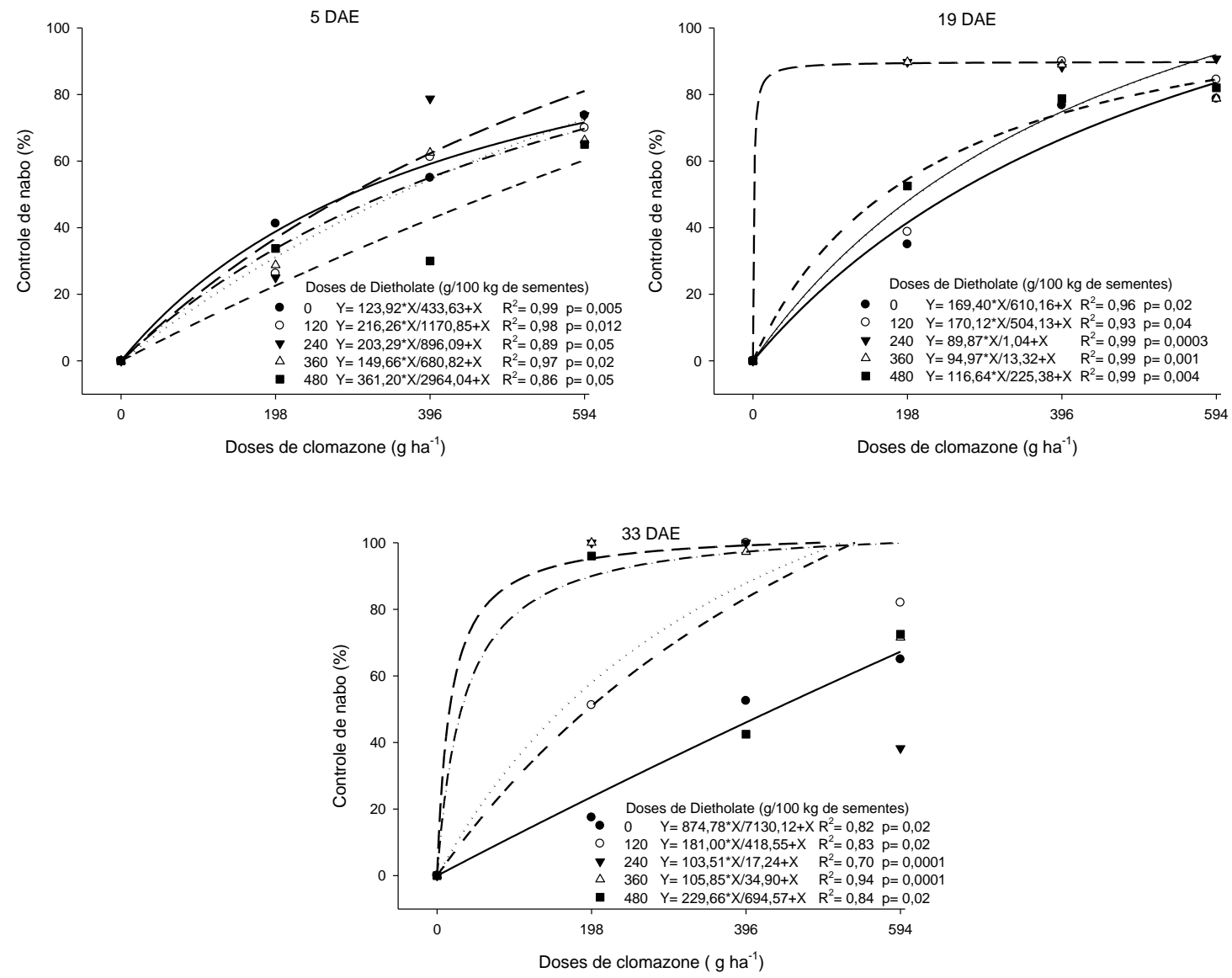

Figura 1. Controle (\%) de nabo (Raphanus sativus) em função da aplicação de doses de clomazone associadas a doses de dietholate em tratamento de sementes de trigo cultivar TBIO Itaipu, aos 5, 19 e 33 dias após a emergência da cultura (DAE). UFFS, Erechim, RS, 2014.

Figure 1. Control of turnip (Raphanus sativus) (\%) as a function of the application of clomazone doses associated with dietholate doses in treatment of seeds of wheat cultivar TBIO Itaipu at 5, 19, and 33 days after crop emergence (DAE). UFFS, Erechim, RS, 2014.

No que diz respeito à sensibilidade de plantas daninhas a herbicidas, GALON et al. (2016) verificaram que Digitaria ciliaris, Urochloa plantaginea e Ipomoea indivisa demonstram tolerância diferenciada aos herbicidas inibidores de carotenoides, mecanismo de ação ao qual pertence o clomazone, o que corrobora os resultados encontrados no presente estudo.

Os resultados mostram que as associações dos tratamentos de clomazone ( $\left.\mathrm{g} \mathrm{ha}^{-1}\right)$ e de dietholate (g por $100 \mathrm{~kg}$ de sementes de trigo) nas doses de $198+240,198+360,396+120$ e $396+240$ ocasionaram a morte das plantas de nabo, evitando o acúmulo de massa seca da parte aérea (Tabela 1). Nos demais tratamentos, o acúmulo de massa seca ficou em patamares intermediários ou superiores aos relatados anteriormente. WESTBERG et al. (1989), ao testarem o clomazone para controle de várias espécies de plantas daninhas, também encontraram respostas diferenciadas, ou seja, quando o herbicida foi aplicado de modo isolado, demonstrou em algumas situações maior eficiência e, em outras, menor quando aplicado na mesma espécie. KRUSE et al. (2001) relatam que a eficácia do clomazone pode estar 
associada, além da espécie e do seu estádio de desenvolvimento, também às características de solo, clima, cobertura vegetal, entre outros.
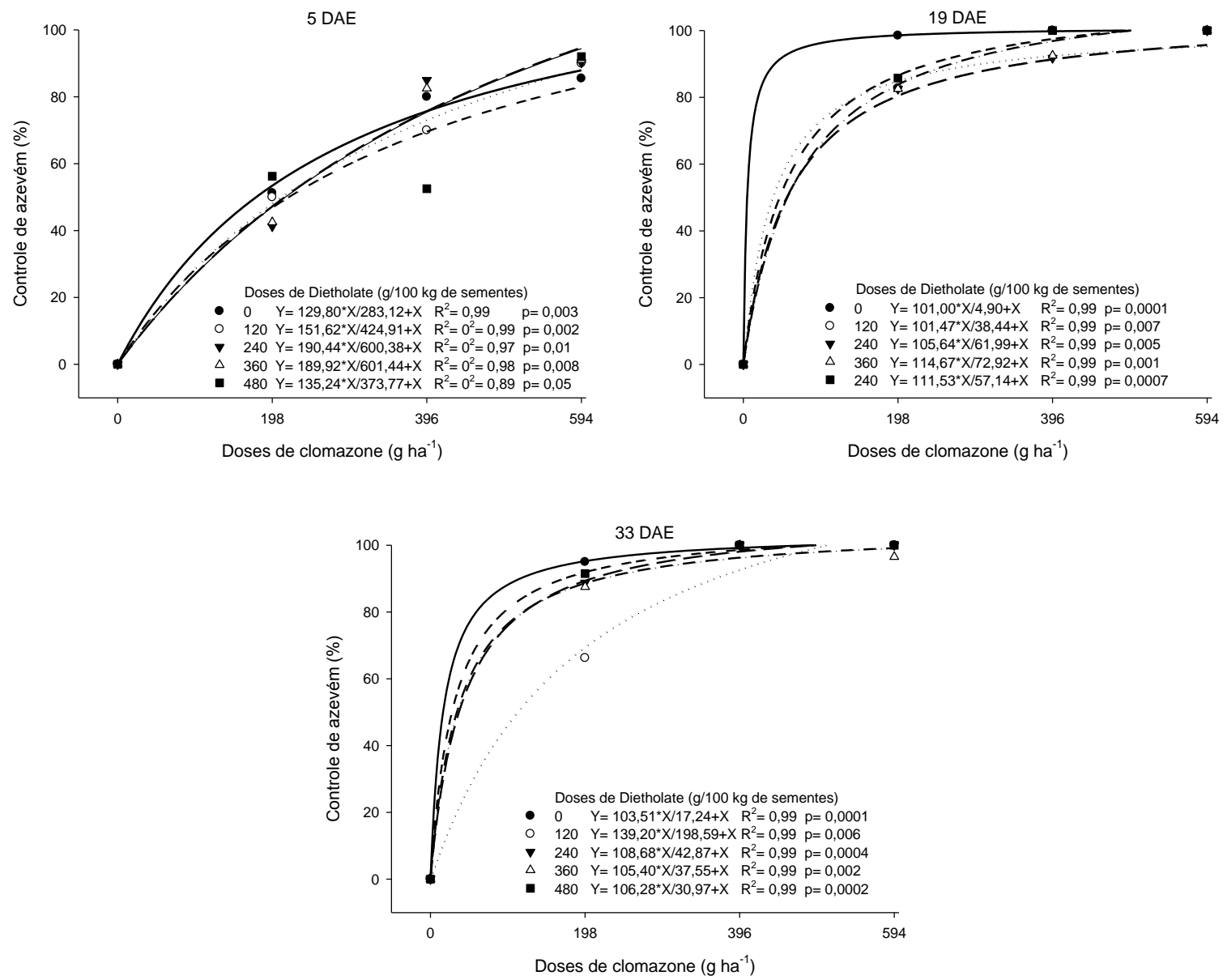

Figura 2. Controle de azevém (Lolium multiflorum) (\%) em função da aplicação de doses de clomazone associadas a doses de dietholate em tratamento de sementes de trigo cultivar TBIO Itaipu, aos 5, 19 e 33 dias após a emergência da cultura (DAE). UFFS, Erechim, RS, 2014.

Figure 2. Control of ryegrass (Lolium multiflorum) (\%) as a function of the application of clomazone doses associated with dietholate doses in the treatment of seeds of wheat cultivar TBIO Itaipu at 5, 19, and 33 days after crop emergence (DAE). UFFS, Erechim, RS, 2014.

Tabela 1. Massa seca da parte aérea ( $\mathrm{g}$ por vaso) de nabo (Raphanus sativus) em função da aplicação de clomazone associado ao dietholate em tratamento de sementes de trigo, aos 45 dias após a emergência (DAE). UFFS, Campus Erechim, RS, 2014.

Table 1. Dry mass of radish shoots (Raphanus sativus) as a function of the application of clomazone associated with dietholate in the treatment of wheat seeds at 45 days after crop emergence (DAE). UFFS, Campus Erechim, RS, 2014.

\begin{tabular}{|c|c|c|c|c|c|}
\hline \multirow{2}{*}{$\begin{array}{c}\text { Clomazone } \\
\left(\mathrm{g} \mathrm{ha}^{-1}\right)\end{array}$} & \multicolumn{5}{|c|}{ Dietholate ( $\mathrm{g} / 100 \mathrm{~kg}$ de sementes) } \\
\hline & 0 & 120 & 240 & 360 & 480 \\
\hline & \multicolumn{5}{|c|}{ 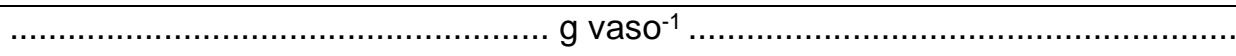 } \\
\hline 0 & $4,38 b^{1}$ & - & - & - & - \\
\hline 198 & $5,00 \mathrm{aA}$ & $4,85 \mathrm{aA}$ & $0,00 \mathrm{bB}$ & $0,00 \mathrm{bB}$ & $0,04 \mathrm{cB}$ \\
\hline 396 & $4,98 \mathrm{aA}$ & $0,00 \mathrm{cB}$ & $0,00 \mathrm{bB}$ & $0,10 \mathrm{bB}$ & 5,27 aA \\
\hline 594 & $4,36 \mathrm{bB}$ & $1,64 \mathrm{bD}$ & $6,50 \mathrm{aA}$ & $2,72 \mathrm{aC}$ & $4,22 \mathrm{bB}$ \\
\hline Média Geral & \multicolumn{5}{|c|}{2,20} \\
\hline CV $(\%)$ & \multicolumn{5}{|c|}{13,20} \\
\hline
\end{tabular}

${ }^{1}$ Médias seguidas de mesmas letras minúsculas na coluna, comparando as doses do clomazone dentro de cada dose de dietholate, e maiúsculas na linha, comparando as doses do dietholate dentro de cada dose de clomazone, não diferem pelo teste de Tukey a $5 \%$ de probabilidade. 
As plantas que se recuperaram da exposição ao herbicida conseguiram, em alguns casos, acumular maior quantidade da massa seca do que a testemunha sem herbicida e sem o protetor (Tabela 1). Esse fato decorre da competição que existe entre as espécies envolvidas na comunidade, ou seja, as plantas de nabo, de trigo e de azevém, quando presentes na mesma unidade experimental, passam a disputar os recursos do meio, como água, luz e nutrientes. RIGOLI et al. (2008) também observaram haver competição quando o trigo, o nabo e o azevém conviveram em comunidade, ao avaliarem o acúmulo de massa seca da parte aérea das espécies.

De maneira geral, o uso de maiores doses de dietholate, mesmo associadas às maiores doses de clomazone, ocasionou maior acúmulo de massa seca do nabo, ao se compararem as menores doses do protetor dentro de cada dose do herbicida (Tabela 1). Esse fato leva a supor que o dietholate também conseguiu proteger o nabo do efeito do herbicida, principalmente nas maiores doses do protetor. Ressaltase que não se deseja que o safener proteja a planta daninha do efeito do herbicida, e sim somente a cultura. Assim, deve-se tomar o cuidado, nas lavouras, para que não haja o favorecimento do nabo em detrimento dessa proteção. KARAM et al. (2003) já salientavam essa preocupação ao trabalharem com o dietholate como protetor dos efeitos do clomazone quando aplicados na cultura do milho.

Aos 45 DAE, verificou-se em geral que o aumento das doses de clomazone associado ou não às doses de dietholate ocasionou a redução do acúmulo de massa seca do azevém (Tabela 2), evidenciando assim o controle da planta daninha. Esses resultados indicam a boa ação graminicida desse herbicida em aplicações em pré-emergência, pois, mesmo em baixas doses (198 $\left.\mathrm{g} \mathrm{ha}^{-1}\right)$, a maior massa seca obtida foi reduzida em 5,8 vezes em comparação à testemunha infestada. Ressalta-se assim a importância desse resultado, já que na atualidade o azevém apresenta resistência aos herbicidas inibidores de ALS, ACCase e EPSPs no Estado do Rio Grande do Sul (ROMAN et al. 2004, VARGAS et al. 2013); por ser o clomazone inibidor de carotenoide, tem-se uma opção interessante para o controle químico dessa planta daninha infestante de culturas semeadas no inverno. Corroboram o presente resultado os encontrados por GALON et al. (2015) ao aplicarem o clomazone ( $\left.800 \mathrm{~g} \mathrm{ha}^{-1}\right)$ em pré-emergência de azevém e trigo, que verificaram eficiência igual ou superior a $96 \%$ da planta daninha aos 28 dias após a aplicação dos tratamentos, demonstrando assim a elevada eficácia desse produto.

Tabela 2. Massa seca da parte aérea de azevém (Lolium multiflorum) em função da aplicação de clomazone em pré-emergência associado ao dietholate em tratamento de sementes de trigo, aos 45 dias após a emergência (DAE). UFFS, Campus Erechim, RS, 2014.

Table 2. Dry mass of ryegrass shoots (Lolium multiflorum) as a function of the application of clomazone associated with dietholate in the treatment of wheat seeds at 45 days after crop emergence (DAE). UFFS, Campus Erechim, RS, 2014.

\begin{tabular}{|c|c|c|c|c|c|}
\hline \multirow{2}{*}{$\begin{array}{l}\text { Clomazone } \\
\left(\mathrm{g} \mathrm{ha}^{-1}\right)\end{array}$} & \multicolumn{5}{|c|}{ Dietholate (g/100 kg de sementes) } \\
\hline & 0 & 120 & 240 & 360 & 480 \\
\hline & \multicolumn{5}{|c|}{ 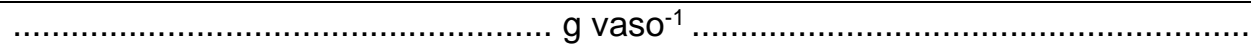 } \\
\hline 0 & $4,79 \mathrm{a}^{1}$ & - & - & - & - \\
\hline 198 & $0,00 \mathrm{bC}$ & $0,42 \mathrm{aB}$ & $0,50 \mathrm{aAB}$ & $0,69 \mathrm{aAB}$ & 0,83 aA \\
\hline 396 & $0,00 \mathrm{bA}$ & $0,18 a b A$ & $0,25 a b A$ & $0,15 \mathrm{bcA}$ & $0,12 \mathrm{bcA}$ \\
\hline 594 & $0,05 \mathrm{bB}$ & $0,34 \mathrm{aAB}$ & $0,17 \mathrm{bAB}$ & $0,36 \mathrm{bAB}$ & $0,40 \mathrm{bA}$ \\
\hline Média Geral & \multicolumn{5}{|c|}{0,46} \\
\hline CV (\%) & \multicolumn{5}{|c|}{37,08} \\
\hline
\end{tabular}

${ }^{1}$ Médias seguidas de mesmas letras minúsculas na coluna, comparando as doses do clomazone dentro de cada dose de dietholate, e maiúsculas na linha, comparando as doses do dietholate dentro de cada dose de clomazone, não diferem pelo teste de Tukey a $5 \%$ de probabilidade.

Os resultados demonstram que todas as doses de dietholate, ao se comparar dentro de cada dose de clomazone, não diferiram significativamente para o acúmulo de massa seca de azevém, exceto o uso de $120 \mathrm{~g} / 100 \mathrm{~kg}$ de sementes, em que a massa seca foi superior à da testemunha sem aplicação do safener e menor que a maior dose do protetor (Tabela 2). Dessa maneira, pode-se relatar que o uso da maior dose de dietholate, quando associada à maior dose de clomazone $\left(594 \mathrm{~g} \mathrm{ha}^{-1}\right)$, provocou maior acúmulo da massa seca do azevém, ocasionando assim efeito protetor da planta daninha, o que não se deseja para o seu controle. Essa resposta também ocorreu com a massa seca do nabo (Tabela 1), onde a maior dose do protetor ocasionou proteção da planta daninha; conforme mencionado, essa situação não é desejada. 
No que se refere ao controle de nabo aos 21, 28, 35 e 42 DAE, no experimento adicional, ao se comparar a melhor dose-resposta de clomazone associado ao dietholate, verificou-se que todos os herbicidas controlaram de forma eficiente a planta daninha a partir dos 28 DAE, observando-se controle superior a 94,75\% (Tabela 3). A partir dos $35 \mathrm{DAE}$, observou-se que todos os tratamentos, exceto a testemunha infestada, ocasionaram controle de 100\% das plantas de nabo. ARDUIM et al. (2012), ao trabalharem com a eficiência de pyroxsulam no controle das plantas daninhas infestantes da cultura do trigo, R. raphanistrum (nabo), Glycine max (soja voluntária) e Polygonum convolvulus (erva-de-bicho), constataram que ele proporcionou controle superior a $80 \%$, o que corrobora os resultados encontrados no presente estudo.

Tabela 3. Controle (\%) de nabo (Raphanus sativus) em função da aplicação de herbicidas. UFFS, Campus Erechim, RS, 2014.

Table 3. Control (\%) of turnip (Raphanus sativus) as a function of herbicide application. UFFS, Campus Erechim RS, 2014.

\begin{tabular}{lccccc}
\hline Tratamentos & Dose $\left(\mathrm{g} \mathrm{ha}^{-1}\right)$ & $21 \mathrm{DAE}^{1}$ & $28 \mathrm{DAE}$ & $35 \mathrm{DAE}$ & \multicolumn{1}{c}{ 42 DAE } \\
\hline Testemunha infestada & -- & $0,00 \mathrm{c}^{2}$ & $0,00 \mathrm{c}$ & $0,00 \mathrm{~b}$ & $0,00 \mathrm{~b}$ \\
Testemunha capinada & -- & $100,00 \mathrm{a}$ & $100,00 \mathrm{a}$ & $100,00 \mathrm{a}$ & $100,00 \mathrm{a}$ \\
Clomazone + dietholate & $396+240$ & $90,75 \mathrm{a}$ & $97,50 \mathrm{ab}$ & $100,00 \mathrm{a}$ & $100,00 \mathrm{a}$ \\
lodosulfuron-methyl & 05 & $70,00 \mathrm{~b}$ & $98,00 \mathrm{ab}$ & $100,00 \mathrm{a}$ & $100,00 \mathrm{a}$ \\
Pyroxsulam & 18 & $72,50 \mathrm{~b}$ & $94,75 \mathrm{~b}$ & $100,00 \mathrm{a}$ & $100,00 \mathrm{a}$ \\
\hline Média Geral & & 66,65 & 78,05 & 80,00 & 80,00 \\
CV (\%) & & 6,37 & 2,57 & 0,28 & 0,28 \\
\hline
\end{tabular}

${ }^{1}$ DAE: dias após a emergência do nabo. ${ }^{2}$ Médias seguidas de mesmas letras minúsculas na coluna não diferem entre si pelo teste de Tukey a $5 \%$ de probabilidade.

De acordo com OLIVEIRA et al. (2009) e MACIEL et al. (2013), 80\% é o percentual mínimo que determinado herbicida deve apresentar para ser recomendado para o controle de plantas daninhas infestantes de culturas. Assim, todos os tratamentos que envolveram 0 uso de herbicidas (clomazone+dietholate, iodosulfuron-methyl e pyroxsulam) apresentaram índice de controle superior a $80 \%$, em especial a partir dos 28 DAE.

O menor controle observado ao aplicar sobre o nabo os herbicidas inibidores de ALS (iodosulfuronmethyl e pyroxsulam) na primeira avaliação, efetuada aos $21 \mathrm{DAE}$, deve-se ao fato de que os produtos pertencentes a esse mecanismo de ação normalmente levam algumas semanas para manifestarem os efeitos de injúrias sobre as plantas (RODRIGUES \& ALMEIDA 2011). Esse fato foi também observado por GALON et al. (2009) ao avaliarem sintomas de injúrias de trifloxysulfuron-sodium (inibidor de ALS) sobre as cultivares de cana-de-açúcar SP80-1816, RB855113 e RB867515, em comparação com herbicidas de outros mecanismos de ação.

O eficiente controle do nabo com os herbicidas iodosulfuron-methyl e pyroxsulam, ambos inibidores da enzima ALS, se deu em razão de o biótipo utilizado no experimento ser suscetível a esse mecanismo de ação. No entanto, de acordo com PANDOLFO et al. (2013), já existem biótipos de $R$. sativus com elevada resistência ao grupo de herbicidas pertencentes às imidazolinonas e intermediária para as sulfonilureias, ambos inibidores de ALS. COSTA \& RIZZARDI (2014), ao avaliarem os níveis de resistência de $R$. raphanistrum, observaram que, além da resistência às imidazolinonas e sulfonilureias, biótipos dessa planta daninha também mostraram resistência às triazolpirimidinas. Nesse sentido, o clomazone (inibidor de carotenoide) pode ser uma ferramenta alternativa para o manejo, ou até mesmo auxiliar, evitando a disseminação generalizada desses biótipos resistentes à ALS.

O controle de azevém aos $21,28,35$ e 42 DAE ocasionado pelos tratamentos testados no ensaio adicional, comparado com a melhor dose-resposta de clomazone associado ao dietholate, é apresentado na Tabela 4. O azevém foi controlado de forma eficiente pelo clomazone + dietholate a partir dos 21 DAE, chegando a $100 \%$ aos 35 DAE. Contudo, quando se usou o iodosulfuron-methyl e pyroxsulam, foram obtidos controles acima de $80 \%$ a partir dos $35 \mathrm{DAE}$, porém sempre inferiores ao uso de clomazone associado ao dietholate. Os resultados avaliados aos 42 DAE demonstram que a associação do herbicida clomazone com o protetor ocasionou controle superior a 96\%, destacando-se como o melhor tratamento entre os herbicidas aplicados sobre o azevém, sendo inferior somente à testemunha capinada. Esse resultado comprova a excelente ação do clomazone sobre o azevém, como descrito também por BOND et 
al. (2014). O uso de clomazone, conforme relatado, além da melhor eficácia sobre o azevém, quando comparado a iodosulfuron-methyl e pyroxsulam, pode ser uma alternativa de controle de biótipos resistentes aos herbicidas inibidores de EPSPs, ALS e ACCase, por ser uma molécula com outro mecanismo de ação.

Tabela 4. Controle (\%) de azevém (Lolium multiflorum) em função da aplicação de diferentes herbicidas. UFFS, Campus Erechim, RS, 2014.

Table 4. Control (\%) of ryegrass (Lolium muliflroum) as a function of herbicide application. UFFS, Campus Erechim, RS, 2014.

\begin{tabular}{lcrrrr}
\hline Tratamentos & Dose $\left(\mathrm{g} \mathrm{ha}^{-1}\right)$ & $21 \mathrm{DAE}^{1}$ & $28 \mathrm{DAE}$ & 35 DAE & \multicolumn{1}{c}{$42 \mathrm{DAE}$} \\
\hline Testemunha infestada & -- & $0,00 \mathrm{~d}^{2}$ & $0,00 \mathrm{c}$ & $0,00 \mathrm{~d}$ & $0,00 \mathrm{e}$ \\
Testemunha capinada & --- & $100,00 \mathrm{a}$ & $100,00 \mathrm{a}$ & $100,00 \mathrm{a}$ & $100,00 \mathrm{a}$ \\
Clomazone + dietholate & $396+240$ & $91,75 \mathrm{a}$ & $98,00 \mathrm{a}$ & $100,00 \mathrm{a}$ & $96,25 \mathrm{~b}$ \\
lodosulfuron-methyl & 05 & $20,00 \mathrm{c}$ & $80,00 \mathrm{~b}$ & $88,25 \mathrm{~b}$ & $83,75 \mathrm{~d}$ \\
Pyroxsulam & 18 & $32,50 \mathrm{~b}$ & $77,75 \mathrm{~b}$ & $80,00 \mathrm{c}$ & $86,75 \mathrm{c}$ \\
\hline Média Geral & & 48,85 & 71,15 & 73,65 & 73,35 \\
CV (\%) & 8,77 & 8,82 & 3,49 & 1,13 \\
\hline
\end{tabular}

${ }^{1}$ Dias após a emergência do azevém. ${ }^{2}$ Médias seguidas de mesmas letras minúsculas na coluna não diferem entre si pelo teste de Tukey a $5 \%$ de probabilidade.

As plantas de nabo e azevém se mostraram sensíveis aos herbicidas após os 28 DAE (Tabelas 3 e 4), destacando-se que para o nabo foram atingidos índices de controle superiores a 94\% e, para o azevém, $77 \%$ nessa época. Estudos mostram que a resistência de biótipos de azevém aos herbicidas inibidores da ALS é variável, o que se deve ao metabolismo diferenciado da molécula de herbicida, não permitindo que este atinja o sítio de ação. Assim, em biótipos de azevém que apresentem alguma resistência aos herbicidas inibidores da ALS, é necessário maior translocação do produto para a sua plena ação no controle (YU et al. 2008). Isso pode explicar a menor eficiência no controle do azevém pelos herbicidas iodosulfuronmethyl e pyroxsulam, sobretudo nas primeiras épocas de avaliação. $O$ uso do dietholate associado ao clomazone não promoveu redução da eficácia do herbicida no controle das plantas de nabo e de azevém. Isso é importante, uma vez que não é desejável que o safener exerça qualquer influência sobre a eficácia do herbicida no controle das plantas daninhas.

As massas secas de nabo, azevém e trigo avaliadas aos 45 DAE, comparando-se a melhor doseresposta de clomazone + dietholate e os tratamentos no experimento adicional, estão apresentadas na Tabela 5. Todos os herbicidas testados ocasionaram menor acúmulo de massa seca do trigo, nabo e azevém. O maior acúmulo de massa seca de trigo foi obtido quando se manteve a cultura livre de plantas daninhas, e os herbicidas não diferiram entre si, o que provocou redução no acúmulo de massa seca igual a manter a cultura convivendo com nabo e azevém.

Tabela 5. Massa seca da parte aérea de trigo cultivar TBIO Itaipu, de nabo (Raphanus sativus) e de azevém (Lolium multiflorum) em função da aplicação de herbicidas aos 45 dias após a emergência. UFFS, Campus Erechim, RS, 2014.

Table 5. Dry mass of shoots of wheat 'TBIO Itaipu', radish (Raphanus sativus) and ryegrass (Lolium multiflorum) as a function of the application of herbicides at 45 days after emergence. UFFS, Campus Erechim, RS, 2014.

\begin{tabular}{lcccc}
\hline Tratamentos & $\begin{array}{c}\text { Dose } \\
\mathrm{g} \mathrm{ha}^{-1}\end{array}$ & $\begin{array}{c}\text { Massa seca do } \\
\text { trigo }\left(\mathrm{g} \mathrm{vaso}^{-1}\right)\end{array}$ & $\begin{array}{c}\text { Massa seca do } \\
\text { nabo }(\mathrm{g} \text { vaso- }\end{array}$ & $\begin{array}{c}\text { Massa seca do } \\
\text { azevém }\left(\mathrm{g} \mathrm{vaso}^{-1}\right)\end{array}$ \\
\hline Testemunha infestada & --- & $1,50 \mathrm{~b}^{1}$ & $4,38 \mathrm{a}$ & $4,50 \mathrm{a}$ \\
Testemunha capinada & --- & $6,28 \mathrm{a}$ & $0,00 \mathrm{~b}$ & $0,00 \mathrm{c}$ \\
Clomazone + dietholate & $396+240$ & $0,86 \mathrm{~b}$ & $0,00 \mathrm{~b}$ & $0,25 \mathrm{C}$ \\
lodosulfuron-methyl & 5 & $0,80 \mathrm{~b}$ & $0,00 \mathrm{~b}$ & $1,60 \mathrm{~b}$ \\
Pyroxsulam & 18 & $2,35 \mathrm{~b}$ & $0,00 \mathrm{~b}$ & $1,22 \mathrm{~b}$ \\
\hline Média Geral & & 2,36 & 0,88 & 0,95 \\
CV $(\%)$ & 44,50 & 51,50 & 18,78 \\
\hline
\end{tabular}

${ }^{1}$ Médias seguidas de mesmas letras minúsculas na coluna não diferem entre si pelo teste de Tukey a $5 \%$ de probabilidade. 
No tocante à massa seca do nabo, observou-se que todos os herbicidas ocasionaram a morte completa das plantas, igualando-se à testemunha capinada, como expresso também com relação ao controle de $100 \%$ relatado na Tabela 3. Em azevém, o clomazone + dietholate foi o que mais reduziu o acúmulo de massa seca, o que corrobora o elevado índice de controle demonstrado por esse tratamento na Tabela 4. O iodosulfuron-methyl e o pyroxsulam não diferiram entre si, apresentando redução de massa seca do azevém de 2,8 e 3,7 vezes, respectivamente, em comparação com a testemunha infestada.

\section{CONCLUSÃO}

O tratamento das sementes de trigo com dietholate não interferiu no controle de azevém e de nabo pelo clomazone aplicado em pré-emergência. O efeito do herbicida sobre o nabo foi razoável: as plantas tratadas apresentaram capacidade de recuperação dos efeitos fitotóxicos no decorrer das avaliações. $O$ azevém apresenta elevada sensibilidade ao clomazone; baixas doses do herbicida apresentam excelente controle, demonstrando potencial para manejar biótipos resistentes aos herbicidas pertencentes aos inibidores de EPSPs, ALS e ACCase. O iodosulfuron-methyl e o pyroxsulam apresentaram excelente ação sobre o nabo e satisfatório controle de azevém. $O$ uso de doses elevadas de dietholate $(480 \mathrm{~g} / 100 \mathrm{~kg}$ de sementes) ocasiona a proteção das plantas daninhas nabo e azevém, com maior produção de sua massa seca, o que não é desejável.

\section{AGRADECIMENTOS}

Ao CNPq, à FAPERGS e ao FINEp, pela concessão de auxílio financeiro à pesquisa e pelas bolsas concedidas.

\section{REFERÊNCIAS}

AGOSTINETTO D et al. 2008. Período crítico de competição de plantas daninhas com a cultura do trigo. Planta Daninha 26: 271-278.

ANDRES A et al. 2013. Selectivity and weed control efficacy of pre- and post-emergence applications of clomazone in Southern Brazil. Crop Protection 53: 103-108.

ARDUIM GS et al. 2012. Eficiência do herbicida pyroxsulam no controle de diferentes plantas daninha na cultura do trigo (Triticum aestivum L.). In: 28 CONGRESSO BRASILEIRO DA CIÊNCIA DAS PLANTAS DANINHAS. Resumos... Campo Grande: SBCPD. p. 189-193. (CD-Rom).

BOND JA et al. 2014. Glyphosate-resistant italian ryegrass (Lolium perenne ssp. multiflorum) control with fall-applied residual herbicides. Weed Technology 28: 361-370.

CONAB. 2016. Séries Históricas: Trigo. Disponível em: <http://www.conab.gov.br>. Acesso em: 10 jun. 2016.

COSTA LO \& RIZZARDI MA. 2014. Resistance of Raphanus raphanistrum to the herbicide metsulfuron-methyl. Planta Daninha 32: 181-187.

EMBRAPA. 2013. Centro Nacional de Pesquisa Agropecuária de Solos (Brasília, DF). Sistema brasileiro de classificação de solos. Brasília: Embrapa Produção de Informação; Brasília, DF: Embrapa Solos. 154p.

EMBRAPA. 2011. Sistemas de produção/Embrapa Agropecuária Oeste. Informações técnicas para trigo e triticale safra 2012. Dourados: Embrapa Agropecuária Oeste. 204p.

FERHATOGLU Y et al. 2005. The basic for safening of clomazone by phorate insecticide in cotton and inhibitors of cytochrome P450s. Pesticide Biochemistry and Physiology 81: 59-70.

GALON L et al. 2009. Seletividade de herbicidas a genótipos de cana-de-açúcar. Planta Daninha 27: 1083-1093.

GALON L et al. 2015. Efficacy and phytotoxicity of herbicides applied for the handling of weeds that infest wheat. Revista Brasileira de Herbicidas 14: 128-140.

GALON L et al. 2016. Selectivity and efficiency of herbicides in weed control on sweet sorghum. Pesquisa Agropecuária Tropical 46: 123-131.

LAMEGO FP et al. 2013. Habilidade competitiva de cultivares de trigo com plantas daninhas. Planta Daninha 31: 521 531.

KARAM D et al. 2003. Seletividade da cultura do milho ao herbicida clomazone por meio do uso de dietholate. Revista Brasileira de Milho e Sorgo 2: 72-79.

KRUSE ND et al. 2001. Sinergismo potencial entre herbicidas inibidores do fotossistema ll e da síntese de carotenóides. Ciência Rural 31: 569-575.

MARIANI F et al. 2015. Herança da resistência de Lolium multiflorum ao iodosulfuron- Methyl sodium. Planta Daninha 33: 351-356.

MACIEL CDG et al. 2013. Potencialization of mesotrione efficiency in tank mixture with inhibiting of Photosystem II by distinct absorption pathways of crabgrass. Revista Brasileira de Herbicidas 12: 210-219.

OLIVEIRA AR et al. 2009. Controle de Commelina benghalensis, C. erecta, Tripogandra diurética na cultura do café. Planta Daninha 27: 823-830.

PANDOLFO CE et al. 2013. Limited occurrence of resistant radish (Raphanus sativus) to ahas-inhibiting herbicides in Argentina. Planta Daninha 31: 657-666. 
RIGOLI RP et al. 2008. Habilidade competitiva relativa do trigo (Triticum aestivum) em convivência com azevém (Lolium multiflorum) ou nabo (Raphanus raphanistrum). Planta Daninha 26: 93-100.

RIZZARDI MA \& SERAFINI MC. 2001. Ação do anidrido naftálico na seletividade de herbicidas aplicados para controle de azevém em aveia-branca. Planta Daninha. 19: 367-374.

RODRIGUES BN \& ALMEIDA FR. 2011. Guia de herbicidas. 6.ed. Londrina: Edição dos Autores, 697p.

ROMAN ES et al. 2006. Manejo e controle de plantas daninhas em trigo. Passo Fundo: Embrapa Trigo, 12p. (Documentos Online, 63).

ROMAN ES et al. 2004. Resistência de azevém (Lolium multiflorum) ao herbicida glyphosate. Planta Daninha 22: 301 306.

SANCHOTENE DM et al. 2010. Efeito do protetor dietholate na seletividade de clomazone em cultivares de arroz irrigado. Planta Daninha 28: 339-346.

SILVA FMO et al. 2010. Controle químico de plantas daninhas na cultura da mamoeira. In: 4 CONGRESSO BRASILEIRO DA MAMONA e 1 SIMPÓSIO INTERNACIONAL DE OLEAGINOSAS ENERGÉTICAS. Anais... João pessoa: Embrapa Algodão. p. 1255-1263.

SBCPD - Sociedade Brasileira da Ciência das Plantas Daninhas. 1995. Procedimentos para instalação, avaliação e análise de experimentos com herbicidas. Londrina: SBCPD. 42p.

TENBROOK PL \& TJEERDEMA RS. 2006. Biotransformation of clomazone in rice (Oryza sativa) and early watergrass (Echinochloa oryzoides). Pesticide Biochemistry and Physiology 85: 38-45.

VARGAS L et al. 2013. Dose-response curves of Lolium multiflorum biotypes resistant and susceptible to clethodim. Planta Daninha 31: 887-892.

ZHANG W et al. 2005. Response of rice and barnyardgrass (Echinochloa crus-galli) to rates and timings of clomazone. Weed Technology 19: 528-531.

WESTBERG DE et al. 1989. Weed control with clomazone alone and with other herbicides. Weed Technology 3: 678685.

YU Q et al. 2008. Mutations of the ALS gene endowing resistance to ALS-inhibiting herbicides in Lolium rigidum populations. Pest Management Science 64: 1229-1236.

YUN MS et al. 2005. Cytochrome P-450 monooxygenase activity in herbicide-resistant and susceptible late watergrass (Echinochloa phyllopogon). Pesticide Biochemistry and Physiology 83: 107-114. 